\title{
Proton-Conducting Dense Ceramic Membranes for Hydrogen Separation
}

\section{Technical Progress Report}

\author{
(Annual) \\ $10 / 01 / 02$ \\ $09 / 31 / 03$
}

Jerry Y.S. Lin

Scott Cheng

Vineet Gupta

DE-FG26-00NT40818

\section{Department of Chemical Engineering \\ University of Cincinnati \\ Cincinnati, OH 45221-0171}




\section{DISCLAIMER}

“This report was prepared as an account of work sponsored by an agency of the United States Government. Neither the United States Government nor any agency thereof, nor any of their employees, makes any warranty, express or implied, or assumes any legal liability or responsibility for the accuracy, completeness, or usefulness of any information, apparatus, product, or process disclosed, or represents that its use would not infringe privately owed rights. Reference herein to any specific commercial product, process, or service by trade name, trademark, manufacturer, or otherwise does not necessarily constitute or imply its endorsement, recommendation, or favoring by the United States Government or any agency thereof. The views and opinions of authors expressed herein do not necessarily state or reflect those of the United States Government or any agency thereof." 


\begin{abstract}
Dense perovskite-type structured ceramic membranes, $\mathrm{SrCe}_{0.95} \mathrm{Tm}_{0.05} \mathrm{O}_{3}$ (SCTm), of different thickness, were prepared by the dry-press method. Membrane thickness was varied from $3 \mathrm{~mm}$ to $150 \mu \mathrm{m}$. The hydrogen permeation flux was found to be inversely proportional to the thickness of the dense films, indicating that the bulk diffusion rather than the surface reaction played a dominant role in the $\mathrm{H}_{2}$ transport through these dense membranes within the studied thickness range. Hydrogen permeation flux increases with increasing upstream hydrogen partial pressure and decreasing downstream hydrogen partial pressure. The activation energy for hydrogen permeation through the SCTm membrane is about $116 \mathrm{~kJ} / \mathrm{mol}$ in $600-700{ }^{\circ} \mathrm{C}$ and 16 $\mathrm{kJ} / \mathrm{mol}$ in $750-950{ }^{\circ} \mathrm{C}$. This indicates a change in the electrical and protonic conduction mechanism at around $700{ }^{\circ} \mathrm{C}$. $\mathrm{Pd}-\mathrm{Cu}$ thin films were synthesized with elemental palladium and copper targets by the sequential R.F. sputter deposition on porous substrates. Pd-Cu alloy films could be formed after proper annealing. The deposited $\mathrm{Pd}-\mathrm{Cu}$ films were gas-tight. This result demonstrated the feasibility of obtaining an ultrathin SCTm film by the sequential sputter deposition of $\mathrm{Sr}$, Ce and Tm metals followed by proper annealing and oxidation. Such ultrathin SCTm membranes will offer sufficiently high hydrogen permeance for practical applications.
\end{abstract}




\section{TABLE OF CONTENTS}

Introduction $\quad 2$

Executive Summary $\quad 2$

Experimental 3

Membrane Synthesis 3

Membrane Characterization $\quad 4$

Results And Discussion $\quad 4$

Hydrogen Permeation Experiments on SCTm Membranes Prepared by DryPressing Method

Thin Pd-Cu Membranes Prepared by Sputtering Deposition 7

Conclusions

References 


\section{INTRODUCTION}

Dense proton-conducting ceramic membranes have received increasing interest since Iwahara and coworkers first discovered proton-conduction in $\mathrm{SrCeO}_{3}$ based perovskite type ceramics at high temperatures $\left(>500^{\circ} \mathrm{C}\right)$ in a hydrogen-containing atmosphere [1]. The major problem with the $\mathrm{SrCeO}_{3}$ based ceramic membranes is their low electronic conductivity that leads to low hydrogen permeability. Results obtained in our laboratory show that thulium (Tm) doped $\mathrm{SrCeO}_{3}$ has much improved electronic conductivity and therefore higher hydrogen permeability $[2,3]$. For hydrogen permeation through proton-conducting ceramic membranes the bulk diffusion is more likely to be the rate-limiting step even for the thin membranes because the surface charge transfer reaction for hydrogen requires lower energy as compared to oxygen. Therefore it is expected that reducing membrane thickness can be an effective technique in increasing the hydrogen permeance for the proton conducting ceramic membranes. In the previous year a dry-press method was developed to prepare thin thulium doped $\mathrm{SrCeO}_{3}$ membranes of various thickness and then hydrogen permeation properties of these protonconducting ceramic membranes were studied.

The second part of the work conducted in the previous year was to prepare thin $\mathrm{Pd}-\mathrm{Cu}$ membranes by sputtering method. Pd-Cu alloy membranes have received increasing interest in recent years as compared to other palladium alloy membranes because of its improved chemical stability against surface poisoning. The first objective of this part of the work was to demonstrate the effectiveness of the sputter deposition method to prepare ultrathin $\mathrm{Pd}-\mathrm{Cu}$ membranes on porous supports. The second objective was to test the method of sequential sputter deposition of multiple metals in order to use this method to obtain thin thulium doped $\mathrm{SrCeO}_{3}$ membranes.

\section{EXECUTIVE SUMMARY}

Dense perovskite-type structured ceramic membranes, $\mathrm{SrCe}_{0.95} \mathrm{Tm}_{0.05} \mathrm{O}_{3}(\mathrm{SCTm})$, of different thickness, were prepared by the dry-press method. Membrane thickness was varied from $3 \mathrm{~mm}$ to $150 \mu \mathrm{m}$ by adding the controlled amount of SCTm powder uniformly on the surface of the support layer. The $\mathrm{SrCe}_{0.95} \mathrm{Tm}_{0.05} \mathrm{O}_{3}$ powder was prepared by citrate method with the precursors of metal nitrates. Particle size of the powder was found to be the vital factor in determining the porosity and gas tightness effect of sintered disks. Small particle size formed dense film while large particle size produced porous substrate. Hydrogen permeation studies of the SCTm membranes were done at various operating conditions such as membrane thickness, operating temperature, upstream and downstream hydrogen partial pressure and downstream oxygen partial pressure. The hydrogen permeation flux was found to be inversely proportional to the thickness of the dense films, indicating that the bulk diffusion rather than the surface reaction played a dominant role in the hydrogen transport through these dense membranes within the studied thickness range. A hydrogen permeation flux of $9.37 \times 10^{-8} \mathrm{~mol} / \mathrm{cm}^{2} \cdot \mathrm{s}$ was obtained at $900{ }^{\circ} \mathrm{C}$ with a $150 \mu \mathrm{m}$ thick SCTm membrane when $10 \% \mathrm{H}_{2} / \mathrm{He}$ and air were used as feed gas and sweeping gas respectively. In order to reach the level of commercial interests, the hydrogen permeation flux should be at least $7.4 \times 10^{-7} \mathrm{~mol} / \mathrm{cm}^{2} \cdot \mathrm{s}$. Therefore, by extrapolation of linear inverse relationship between hydrogen flux and membrane dense layer thickness, the membrane thickness should be at least reduced to $15 \mu \mathrm{m}$. Hydrogen permeation flux increases with increasing upstream hydrogen partial pressure and decreasing downstream hydrogen partial 
pressure. The activation energy for hydrogen permeation through the SCTm membrane is about $116 \mathrm{~kJ} / \mathrm{mol}$ in $600-700{ }^{\circ} \mathrm{C}$ and $16 \mathrm{~kJ} / \mathrm{mol}$ in $750-950{ }^{\circ} \mathrm{C}$. This indicates a change in the electrical and protonic conduction mechanism at around $700{ }^{\circ} \mathrm{C}$. The hydrogen flux increases with increasing downstream oxygen partial pressure for all membrane thicknesses studies at oxygen pressure range of $0.1 \mathrm{~atm}$ to $1.0 \mathrm{~atm}$. Based on water production equilibrium equation, the higher downstream oxygen concentration would correspondingly have a lower hydrogen equilibrium concentration, which creates a higher driving force for protonic conduction. The theory also explains tangible hydrogen permeation rate could not be achieved if there is no oxygen at the downstream side of membrane.

$\mathrm{Pd}-\mathrm{Cu}$ thin films were synthesized with elemental palladium and copper targets by the sequential R.F. sputter deposition on porous substrates. Pd-Cu alloy films could be formed after proper annealing. The ratio of the concentration of $\mathrm{Cu}$ to the concentration of $\mathrm{Pd}$ in the deposited layer increases on increasing the ratio of the deposition times for $\mathrm{Cu}$ and $\mathrm{Pd}$ though the increment in the ratio of concentrations of deposited metals is not proportional to the ratio of their corresponding deposited time. This indicates that the composition of the final $\mathrm{Pd}-\mathrm{Cu}$ film can be controlled by the deposition time. This result demonstrated the feasibility of obtaining an ultrathin SCTm film by the sequential sputter deposition of $\mathrm{Sr}$, Ce and $\mathrm{Tm}$ metals followed by proper annealing and oxidation. Such ultrathin SCTm membranes will offer sufficiently high hydrogen permeance for practical applications.

\section{EXPERIMENTAL}

\section{Membrane Synthesis}

The citrate method was used to prepare the perovskite-type $\mathrm{SrCe}_{0.95} \mathrm{Tm}_{0.05} \mathrm{O}_{3}$ powder. $\mathrm{Sr}\left(\mathrm{NO}_{3}\right)_{2}, \mathrm{Ce}\left(\mathrm{NO}_{3}\right)_{3} \cdot 6 \mathrm{H}_{2} \mathrm{O}$ and $\mathrm{Tm}\left(\mathrm{NO}_{3}\right)_{3} \cdot 5 \mathrm{H}_{2} \mathrm{O}$ were mixed in stoichiometric proportions with citric acid in distilled water to form a $0.2 \mathrm{M}$ solution of total metal ions. The molar amount of the citric acid was 1.5 times higher than the total molar amount of the metal ions. This solution was heated to $96{ }^{\circ} \mathrm{C}-100{ }^{\circ} \mathrm{C}$ for $5 \mathrm{~h}$ with stirring in a refluxed mode, where polymerization reaction took place. The water was evaporated and the solution was condensed to a sticky gel. After drying at $110{ }^{\circ} \mathrm{C}$ for $24 \mathrm{~h}$, the gel-like material became a sponge-like and brittle material. It was self-ignited at $400{ }^{\circ} \mathrm{C}$ for $30 \mathrm{~min}$. The material after self-ignition was ground to powder with a mortar and pestle for about $10 \mathrm{~min}$ and calcined at $600^{\circ} \mathrm{C}$ for $10 \mathrm{~h}$ to remove the residual organic compounds.

The raw powder was pressed roughly at a pressure of $5 \mathrm{MPa}$ with a hydraulic press in a die of diameter $25 \mathrm{~mm}$ to form the thick, porous support layer. Another part of the raw powder was carefully ground in an agate mortar for about $15 \mathrm{~min}$. A controlled amount of this powder was added uniformly on the surface of the support layer in the die holder. The two-layer sample in the die holder was pressed again at a final pressure of $130 \mathrm{MPa}$ and finally co-sintered at 1495 ${ }^{\circ} \mathrm{C}$ for $24 \mathrm{~h}$ with a heating and cooling rate of $120{ }^{\circ} \mathrm{C} / \mathrm{h}$.

$\mathrm{Pd}-\mathrm{Cu}$ films were prepared on composite ceramic supports. These supports consist of a porous $\alpha$-alumina disks coated with $\gamma$-alumina on one side. The porous $\alpha$-alumina disks $(2.0 \mathrm{~mm}$ thick and $0.2 \mu \mathrm{m}$ average pore diameter) were prepared by pressing $\alpha$-alumina powder (Alcoa) with a mechanical press at a pressure of $10 \mathrm{MPa}$ followed by sintering at $1150{ }^{\circ} \mathrm{C}$ for $30 \mathrm{~h}$. The membranes were deposited by RF magnetron sputtering using a plasma sciences CRC-150 dc/rf 
magnetron-sputtering unit. Pure copper and palladium foils, $0.1 \mathrm{~mm}$ in thickness, were the elemental targets. Before each run the sputtering chamber was evacuated down to the pressure in the range of $10^{-6}$ Torr for a period of $2 \mathrm{~h}$ and then back filled with UHP argon at a pressure of 5 $\times 10^{-3}$ Torr. The deposition procedure was repeated with switched targets. The multilayer membranes were then annealed in a temperature programmable tubular furnace. The system was heated up to $500-600{ }^{\circ} \mathrm{C}$ at a ramp of $120{ }^{\circ} \mathrm{C} / \mathrm{h}$. The purpose of changing the annealing conditions was to optimize this process with respect to the temperature, time and atmosphere.

\section{Membrane Characterization}

The gas tightness of the membranes was checked by helium permeation method. High temperature hydrogen permeation for SCTm membranes was conducted on the apparatus shown in Figure 1. The sealant was composed of $45 \% \mathrm{SCTb}$ powder, $50 \%$ pyrex glass and $5 \% \mathrm{NaAlO}_{2}$. The sealant powder in desired composition was ground in an agate mortar for several minutes to form a sticky paste. The sticky paste was then put on the top of the inner dense alumina tube (25.4 $\mathrm{mm}$ in OD, from Coors Ceramics). The asymmetrical membrane disk of diameter 21 $\mathrm{mm}$ was put onto the paste. The surface of dense layer of this asymmetrical membrane should be in contact with the paste in order to get complete sealing effect. For metal membranes, the thickness of the deposited film was determined from X-ray diffraction (XRD) pattern $[4,5]$. XRD analysis of membranes was carried out with a Siemens

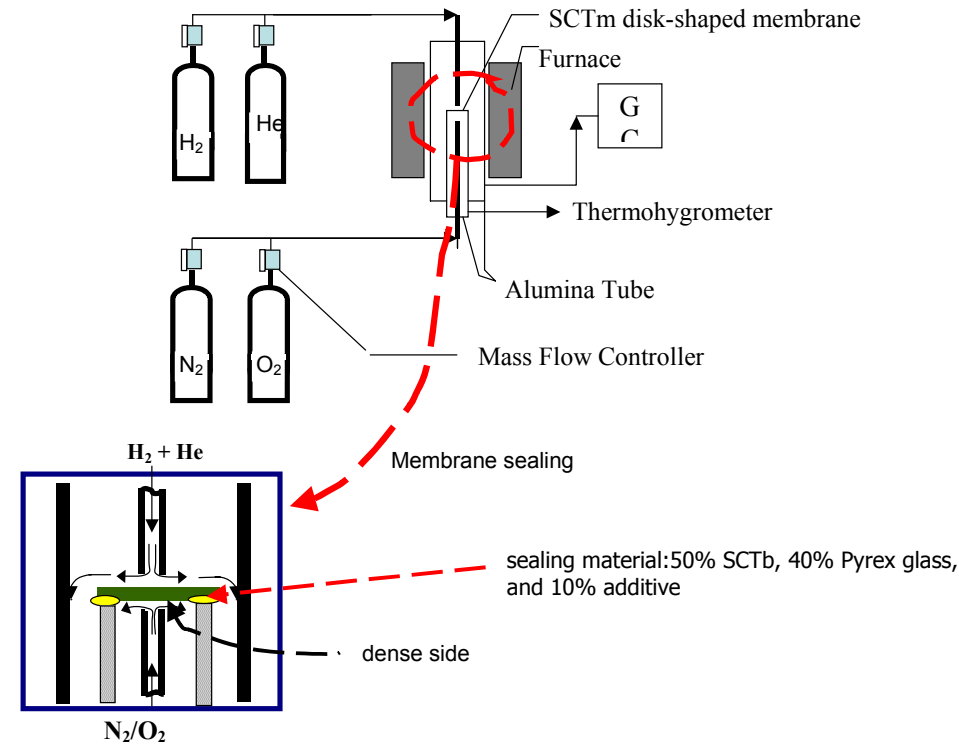

Figure 1 Schematic diagram of hydrogen permeation setup Kristalloflex D500 diffractometer, with $\mathrm{Cu} \mathrm{K} \alpha$ radiation and $2 \theta$ changed from 20 to $70^{\circ}$. The composition of $\mathrm{Cu}$ in $\mathrm{Pd}-\mathrm{Cu}$ was calculated using the relationship between the d-space and the concentration of metal alloys [6].

\section{RESULTS AND DISCUSSION}

\section{Hydrogen Permeation Experiments on SCTm Membranes Prepared by Dry-Pressing Method}

SCTm membranes of different thickness $(3 \mathrm{~mm}$ to $0.15 \mathrm{~mm}$ ) were prepared by the dry-press method. Figure 2 plots hydrogen permeation flux versus the reciprocal of dense film thickness for various samples. This figure clearly shows that the hydrogen permeation flux is linearly proportional to the reciprocal of the membrane thickness in the studied thickness range ( $3 \mathrm{~mm}$ to 
$0.15 \mathrm{~mm}$ ). This relationship confirms that the bulk diffusion is the rate-limiting step for hydrogen permeation through the SCTm membranes.

Figure 3 plots the hydrogen flux versus the reciprocal of temperature for SCTm membranes of different thickness. The hydrogen flux increases linearly with temperatures in the lower temperature zone and it levels off at higher temperature. This is due to the combined effects of the faster rate of hydrogen permeation to the downstream and the less favorable thermodynamic of reaction between hydrogen and oxygen to form water vapor at higher temperatures. Thus, at the higher temperatures the weaker dependency of the observed hydrogen permeation flux is in part due to the higher downstream hydrogen partial pressure corresponding to a lower driving force for hydrogen permeation.

\section{Regression of the data of hydrogen permeation flux versus temperature (at fixed upstream hydrogen pressure), shown in Figure}

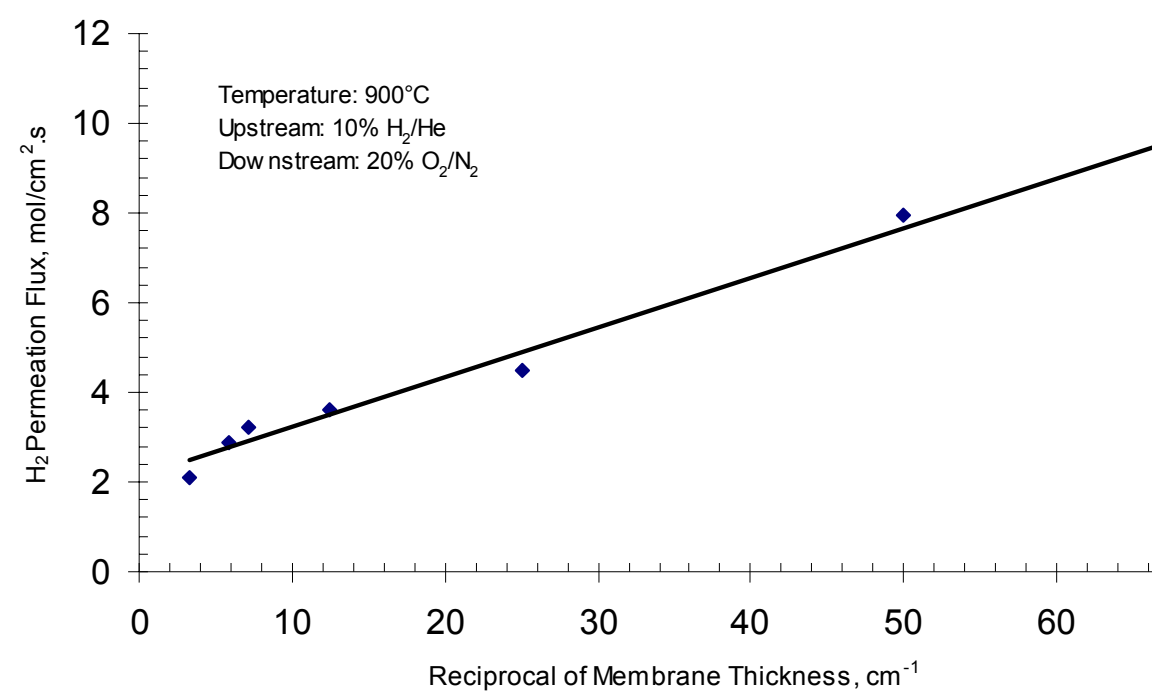

Figure 2 Hydrogen Permeation versus Reciprocal of Dense SCTm Membrane Thickness

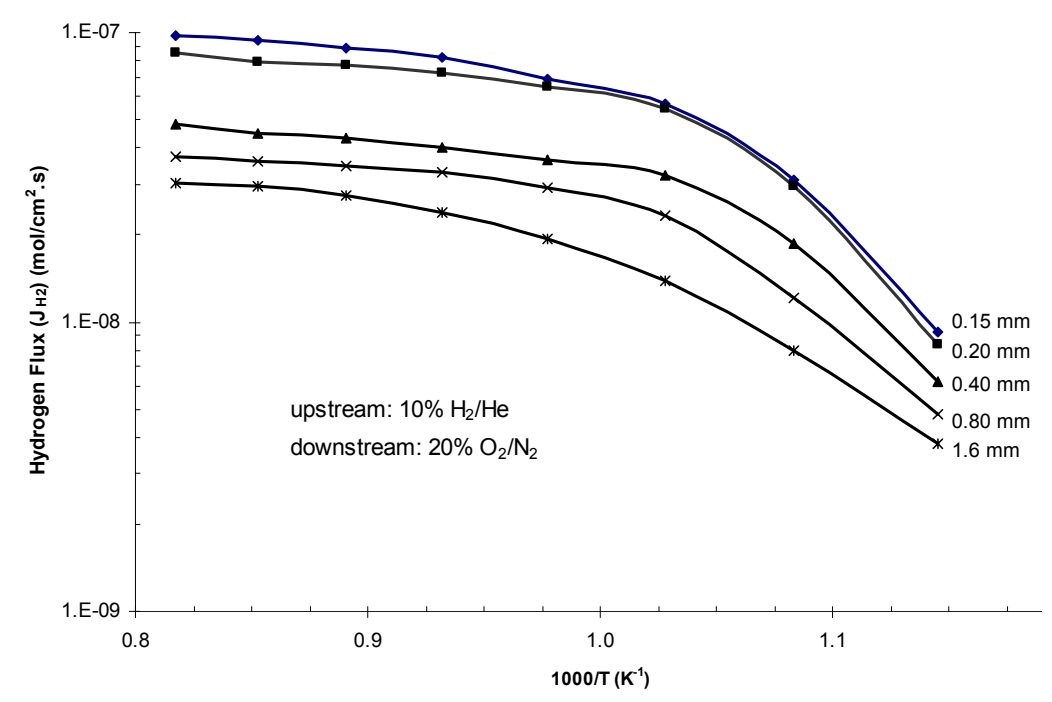

Figure 3 Temperature Dependence of Hydrogen Permeation Flux of SCTm Membranes 3, by the Arrhenius equation, gives the average activation energy for protonic transport. Each curve in Figure 3 can be divided into two straight lines which have different slopes in a lower temperature region $\left(<700^{\circ} \mathrm{C}\right)$ and a higher temperature region $\left(700-950^{\circ} \mathrm{C}\right)$. This indicates a change in the electrical and protonic conduction mechanism at around $700{ }^{\circ} \mathrm{C}$. The activation energy data calculated from the slopes of these lines based on Arrhenius equation are given in Table 1 and Table 2. It shows that the activation energy in the low temperature region (in Table 1) is much higher than the activation energy in the high temperature region (in Table 2). 
Table 1 Activation Energies and Preexponential Constant for SCT Membrane in 600-700 ${ }^{\circ} \mathrm{C}$

\begin{tabular}{|c|l|l|l|l|l|l|}
\hline $\begin{array}{c}\text { Membrane thickness } \\
(\mathrm{mm})\end{array}$ & 0.15 & 0.2 & 0.4 & 0.8 & 1.6 & $\begin{array}{l}\text { Average } \\
\text { value }\end{array}$ \\
\hline $\begin{array}{c}\text { Activation energy E } \\
(\mathrm{kJ} / \mathrm{mol})\end{array}$ & 129.3 & 132.9 & 116.5 & 111.5 & 91.3 & 116.3 \\
\hline $\begin{array}{c}\text { Exponential constant } \\
\mathrm{K}^{0}\left(\mathrm{~mol} / \mathrm{cm}^{2} . \mathrm{s}\right)\end{array}$ & $5.43 \times 10^{-1}$ & $8.12 \times 10^{-1}$ & $6.24 \times 10^{-2}$ & $2.32 \times 10^{-2}$ & $1.11 \times 10^{-3}$ & $2.9 \times 10^{-1}$ \\
\hline
\end{tabular}

Table 2 Activation Energies and Preexponential Constants 3 for SCTm Membrane in $750-950{ }^{\circ} \mathrm{C}$

\begin{tabular}{|c|c|c|c|c|c|c|}
\hline $\begin{array}{c}\text { Membrane thickness } \\
(\mathrm{mm})\end{array}$ & 0.15 & 0.2 & 0.4 & 0.8 & 1.6 & $\begin{array}{c}\text { Average } \\
\text { value }\end{array}$ \\
\hline $\begin{array}{c}\text { Activation energy E } \\
(\mathrm{kJ} / \mathrm{mol})\end{array}$ & 17.46 & 13.09 & 13.97 & 12.32 & 23.35 & 16.04 \\
\hline $\begin{array}{c}\text { Exponential constant } \\
\mathrm{K}^{0}\left(\mathrm{~mol} / \mathrm{cm}^{2} . \mathrm{s}\right)\end{array}$ & $5.57 \times 10^{-7}$ & $3.09 \times 10^{-7}$ & $1.90 \times 10^{-7}$ & $1.28 \times 10^{-7}$ & $3.17 \times 10^{-7}$ & $3.00 \times 10^{-7}$ \\
\hline
\end{tabular}

Figure 4 shows the influence of upstream partial pressure on the hydrogen permeation flux at $900^{\circ} \mathrm{C}$ for SCTm membranes of various thicknesses. The hydrogen flux increases with the upstream partial pressure for all membranes with various thickness. When the hydrogen permeation flux increases with upstream hydrogen partial pressure, the hydrogen equilibrium pressure on downstream also increases. Therefore, the hydrogen permeation flux may turn to level

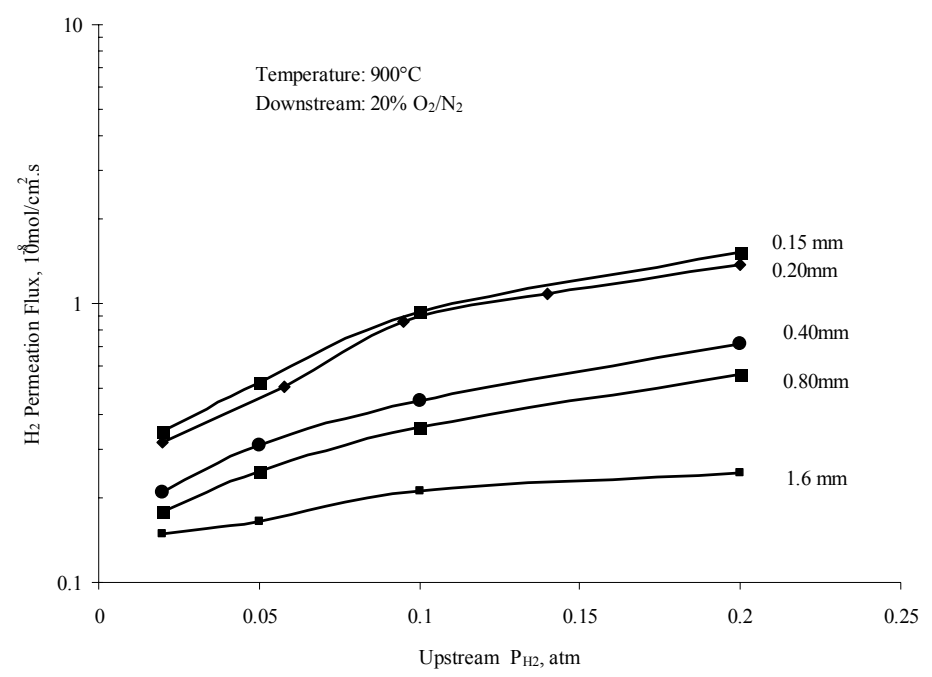
off at higher upstream hydrogen pressure as driving force is reducing. However, this process is rather involved. When a sample of SCTm is exposed to hydrogen and oxygen, it exhibits electron conduction in the hydrogen side and electron-hole conduction in the oxygen side. There are many process variables that are correlated to the hydrogen flux. In addition to the hydrogen and oxygen concentrations, the other parameters that affect the hydrogen flux through these membranes may include the membrane thickness, temperature, electronic and protonic conductivities and the transport coefficients. 
Figure 5 shows the influence of downstream oxygen partial pressure on hydrogen permeation flux for SCTm membranes with various thicknesses. The hydrogen flux increases with increasing downstream oxygen partial pressure for all membrane thicknesses at oxygen pressure range of $0.1 \mathrm{~atm}$ to 1.0 atm. Based on water production equilibrium equation, the higher downstream oxygen concentration would correspondingly have a lower hydrogen equilibrium concentration, which creates a higher driving force for protonic conduction. This relationship also explains why tangible hydrogen permeation rate could not be achieved if there is no oxygen at

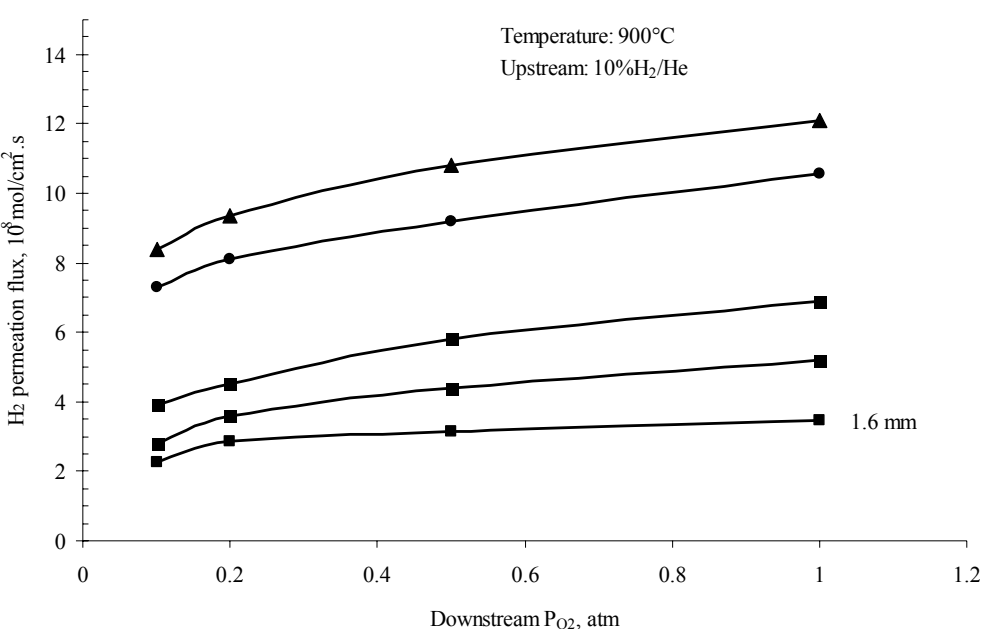

Figure 5 Influence of Downstream Oxygen Partial Pressure on the Hydrogen Permeation Flux of SCTm Membranes downstream. Figure 6 plots hydrogen flux versus downstream hydrogen partial pressure. It can be observed that the hydrogen flux increases when the downstream hydrogen partial pressure decreases.

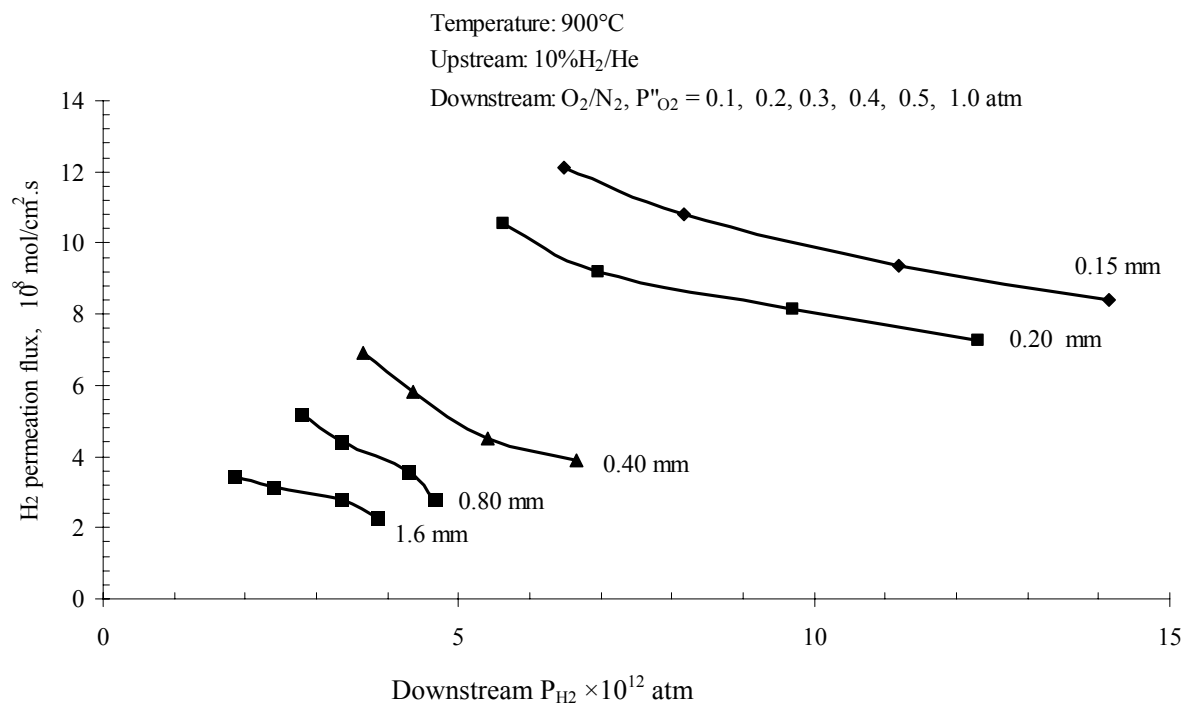

Figure 6 Influence of Downstream Hydrogen Partial Pressure on the Hydrogen Permeation Flux of SCTm Membranes

\section{Thin Pd-Cu Membranes Prepared by Sputtering Deposition}

Table 3 gives the synthetic process and the properties of several $\mathrm{Pd}-\mathrm{Cu}$ membranes prepared with a sequential deposition method. Figure 7 compares the XRD patterns of sample 20. XRD data indicates that the $\mathrm{PdO}$ phase was formed on the membrane sample when 
annealing was carried out in an atmosphere of pure nitrogen at high temperature (referred to as membrane 20A). Formation of PdO can be explained by the fact that the remaining oxygen in the annealing system oxidized Pd at elevated temperature. Subsequently, when the same sample was annealed in the atmosphere of $10 \% \mathrm{H}_{2} / \mathrm{N}_{2}$, the $\mathrm{PdO}$ peak in XRD pattern disappeared (referred to as membrane $20 \mathrm{~B}$ in Figure 7), and an alloy of $\mathrm{Pd}-\mathrm{Cu}$ is formed. This indicates that a reducing atmosphere is indispensable for the formation of $\mathrm{Pd}-\mathrm{Cu}$ alloy.

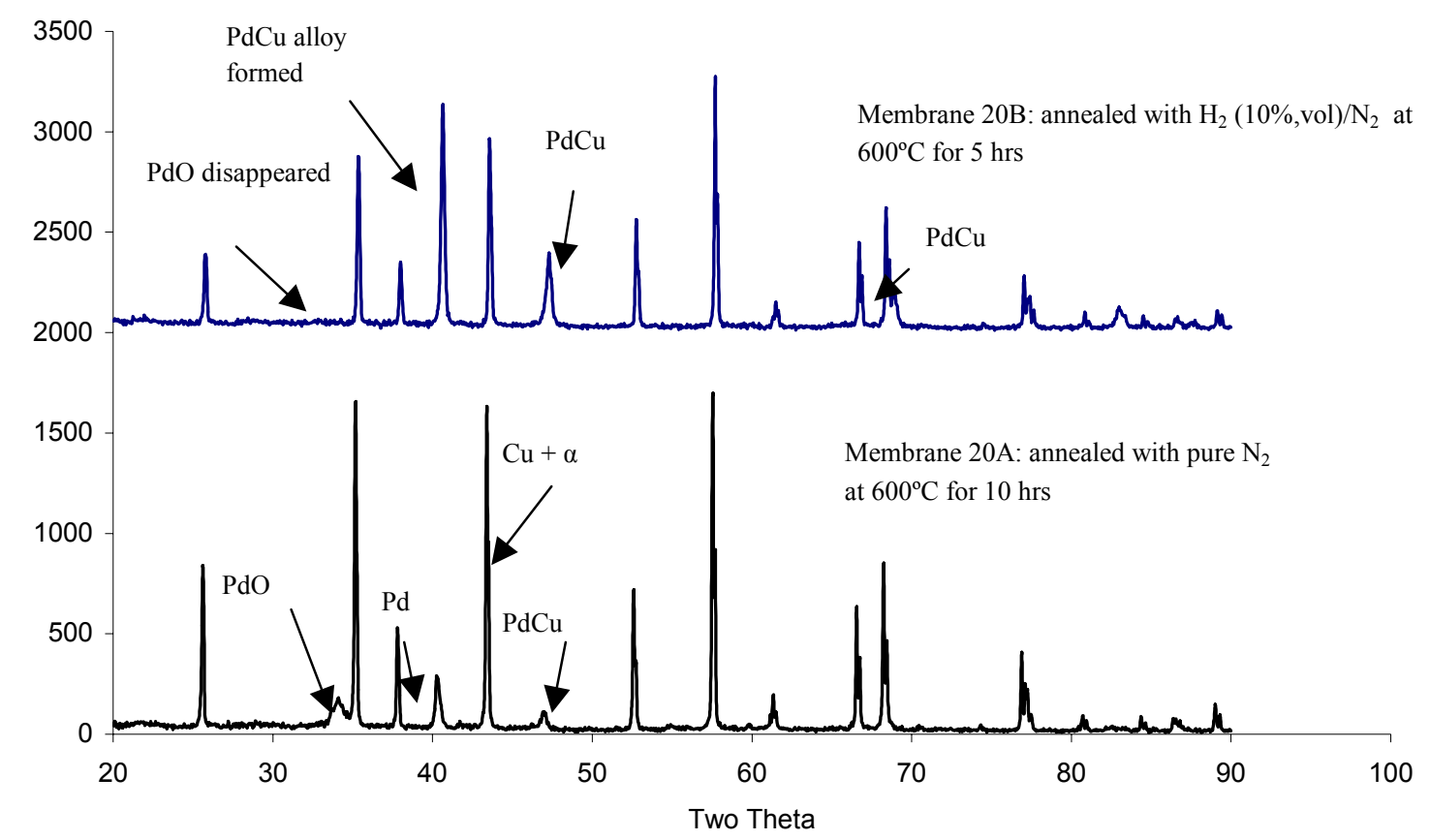

Figure 7 XRD patterns of membrane 20 after annealing under different atmospheres

As summarized in Table 3, the ultrathin Pd-Cu membranes of thickness 70-120 nm can be obtained by the sequential sputter deposition method. The ratio of the concentration of $\mathrm{Cu}$ to the concentration of $\mathrm{Pd}$ in the deposited layer increases on increasing the ratio of the deposition times for $\mathrm{Cu}$ and $\mathrm{Pd}$ though the increment in the ratio of concentrations of deposited metals is not proportional to the ratio of their corresponding deposited time. This indicates that the composition of the final Pd-Cu film can be controlled by the deposition time. All the membranes listed in Table 3 are gas tight to helium. However, the membranes with lower $\mathrm{Cu}$ concentrations delaminated from the support after hydrogen permeation experiments. This can be attributed to the hydrogen embrittlement. The $\mathrm{Pd}-\mathrm{Cu}$ membrane with higher $\mathrm{Cu}$ dopant (40\%) remained intact on the support after hydrogen permeation measurements. This is because doping $\mathrm{Cu}$, similarly to Ag, modifies the metal-hydride temperature two-phase diagram, suppressing hydrogen embrittlement. 
Table 3 Analysis Of The Composition of Pd-Cu Film Deposited by Sequential Sputtering Method

\begin{tabular}{|c|c|c|c|c|c|c|}
\hline Sample & $\begin{array}{l}\text { Total } \\
\text { deposition } \\
\text { time }\end{array}$ & $\begin{array}{l}\text { Deposition } \\
\text { interval } \\
\text { time }\end{array}$ & $\begin{array}{c}\text { Deposition } \\
\text { time ratio } \\
{[\mathrm{Cu} / \mathrm{Pd}]}\end{array}$ & $\begin{array}{l}\text { Measured } \\
{[\mathrm{Cu} / \mathrm{Pd}]} \\
\text { ratio (or } \\
\mathrm{Cu} \%)\end{array}$ & $\begin{array}{c}\text { Thickness } \\
\text { (nm) }\end{array}$ & $\begin{array}{c}\mathrm{Pd}-\mathrm{Cu} \text { layer lamination } \\
\text { situation }\end{array}$ \\
\hline 18 & $\begin{array}{l}8 \min \mathrm{Cu}, \\
20 \min \mathrm{Pd}\end{array}$ & $\begin{array}{l}\mathrm{Cu}: 8 \mathrm{~min} \\
\mathrm{Pd}: 10 \mathrm{~min}\end{array}$ & 0.4 & $0.13(11.9)$ & 76 & $\begin{array}{l}\text { Delaminated after hydrogen } \\
\text { permeation experiment }\end{array}$ \\
\hline 20 & $\begin{array}{l}25 \min \mathrm{Cu} \text {, } \\
45 \min \mathrm{Pd}\end{array}$ & $\begin{array}{l}\mathrm{Cu}: 8 \mathrm{~min} \\
\mathrm{Pd}: 10 \mathrm{~min}\end{array}$ & 0.53 & $0.19(16.2)$ & 94.7 & $\begin{array}{l}20 \% \text { delaminated after hydrogen } \\
\text { permeation experiment, but } \\
\text { totally laminated after subsequent } \\
\text { gas tightness }\end{array}$ \\
\hline 21 & $\begin{array}{l}24 \min \mathrm{Cu} \text {, } \\
30 \min \mathrm{Pd}\end{array}$ & $\begin{array}{l}\mathrm{Cu}: 8 \mathrm{~min} \\
\text { Pd: } 10 \mathrm{~min}\end{array}$ & 0.82 & $0.28(22.4)$ & 116.8 & $\begin{array}{l}\text { Remained intact after initial stage } \\
\text { of hydrogen permeation } \\
\text { experiment, laminated at higher } \\
\text { concentration of } \mathrm{H}_{2}(2 \mathrm{~atm})\end{array}$ \\
\hline 22 & $\begin{array}{l}30 \min \mathrm{Cu} \text {, } \\
14 \min \mathrm{Pd}\end{array}$ & $\begin{array}{l}\mathrm{Cu}: 10 \mathrm{~min} \\
\text { Pd: } 7 \mathrm{~min}\end{array}$ & 2 & $0.66(40.7)$ & 72.6 & $\begin{array}{l}\text { Remained intact after hydrogen } \\
\text { permeation experiments at high } \\
\text { pressure }\left(2 \mathrm{~atm}, 250^{\circ} \mathrm{C}\right)\end{array}$ \\
\hline
\end{tabular}

\section{CONCLUSIONS}

A hydrogen permeation flux of $9.37 \times 10^{-8} \mathrm{~mol} / \mathrm{cm}^{2} \cdot \mathrm{s}$ was obtained at $900{ }^{\circ} \mathrm{C}$ with a 150 $\mu \mathrm{m}$ thick SCTm membrane when $10 \% \mathrm{H}_{2} / \mathrm{He}$ and air were used as feed gas and sweeping gas respectively. The fact that the hydrogen permeation flux was inversely proportional to the thickness of the dense layer suggests the bulk diffusion in SCTm membrane is the rate-limiting step at the studied thickness range. Based on the inverse relation between the membrane thickness and the hydrogen permeation flux, we can extrapolate that the hydrogen flux of value as high as $3 \times 10^{-6} \mathrm{~mol} / \mathrm{cm}^{2} . \mathrm{s}$ (or $4 \mathrm{cc} / \mathrm{cm}^{2} . \mathrm{min}$ ) could be obtained for the SCTm membrane that is $5 \mu \mathrm{m}$ thick at $900^{\circ} \mathrm{C}$. The synthetic procedure of Pd-Cu alloy was established with sputtering deposition system by sequential deposition of the individual elemental targets. The resulting Pd$\mathrm{Cu}$ films are alloy, ultrathin and gas-tight to helium. These results demonstrate the potential to make ultrathin SCTm membranes by the sequential sputter deposition of $\mathrm{Sr}, \mathrm{Ce}$, and $\mathrm{Tm}$ followed by oxidation under controlled conditions.

\section{REFERENCES}

1. S. Humakawa, T. Hibino and H. Iwahara, Electrochemical hydrogen permeation in a protonhole mixed conductor and its application to a membrane reactor, J. Electrochemcial Society, 14 (1994) 1720

2. X. W. Qi and Y.S. Lin, Electric conducting properties of terbium doped strontium cerate, Solid State Ionics, 120, 85-93 (1999) 
3. X.W. Qi and Y.S. Lin, Electrical conduction and hydrogen permeation through mixed proton-electron conducting strontium cerate membranes, Solid State Ionics, 130: (1-2) 149$156(2000)$

4. Y.S. Lin, Chemical and Electrochemical Vapor Deposition of Zirconia-Ytria Solid Solution in Porous Ceramic Media, PhD, Thesis, University of Twente, 1992.

5. B.D. Cullity, "Elements of X-Ray Diffraction", $2^{\text {nd }}$ ed., Addison-Wesley, Reading, MA (1978).

6. C.S. Barrett, T.B. Massalski, Structure of metals: crystallographic methods, principles and data, $3^{\text {rd }}$ ed., Oxford, New York: Paragon, (1980) 